\title{
VESTLUSKAASLASE REAKTSIOONID KURTMISELE KOOLITEEMALISTES ARGIVESTLUSTES ${ }^{1}$
}

\author{
ANDRIELA RÄÄBIS, TIIT HENNOSTE, \\ KIRSI LAANESOO, ANDRA RUMM
}

\begin{abstract}
Annotatsioon. Artiklis käsitleme kurtmisjärjendeid kooliteemalistes eesti argivestlustes. Kurtmisega väljendab suhtleja rahulolematust mingi olukorraga. Kurtja eesmärk on näidata, et kurtmine on põhjendatud, ja võita vestluskaaslase poolehoid. Uurime, kuidas argivestlustes kurtmisele reageeritakse ning kuidas mõjutavad eri tüüpi reaktsioonid kurtmise kulgu. Uurimismaterjal pärineb Tartu Ülikooli suulise eesti keele korpusest ja uurimus põhineb vestlusanalüüsi meetodil. Analüüsist selgub, et kurtmisele järgnevad reaktsioonid moodustavad skaala poolehoiu väljendamine - seisukoha mittevõtmine - vaidlustamine. Lisaks võib vestluspartner küsida lisainfot, olukorda põhjendada või anda nõu probleemi lahendamiseks. Poolehoiu väljendamine on kurtja jaoks eelistatud reaktsioon, mille korral jätkab ta kurtmist. Kurtmist jätkata võimaldavad ka küsimused ja neutraalsed jätkajad. Nõuandeid, seletusi ja kurtmise vaidlustamist kurtja tõrjub ning kurdab enamasti samuti edasi.
\end{abstract}

Võtmesõnad: vestlusanalüüs, suuline keel, kurtmine, järjend, eesti keel

\section{Sissejuhatus}

Artiklis uurime kurtmisjärjendeid kooliteemalistes argivestlustes, keskendudes sellele, kuidas vestluskaaslane kurtmisvoorudele reageerib. Kurtmine (ingl complaint) on suhtlustegevus, millega väljendatakse rahulolematust olukorraga ja pannakse vastutus selle eest kellelegi teisele, nt isikule, organisatsioonile, oludele (Heinemann, Traverso 2009: 2381).

\footnotetext{
Artikli esimene versioon on ette kantud konverentsil ICCA 2018 (Rääbis jt 2018). Artikli valmimist on toetanud Euroopa Liidu Regionaalarengu Fond (Eesti-uuringute Tippkeskus) ja Eesti Teadusagentuur (PUT PRG341). Autorid on anonüümsele retsensendile heade nõuannete eest tänulikud.
} 
Kurtmine sisaldab vähemalt kaht negatiivset komponenti: 1) kurdetakse millegi negatiivse üle ja 2) kõneleja väljendab negatiivset suhtumist (rahulolematus, kurbus, viha jms) kurdetavasse olukorda või selle eest vastutajasse (Drew 1998; Traverso 2009: 2385; Pakkanen 2011: 384). ${ }^{2}$

Kurtmised jagunevad kaheks vastavalt sellele, kes vastutab kurtmise põhjustanud olukorra eest. Ühel juhul on vastutaja (probleemi põhjustaja vms) mõni samas vestluses osaleja. Teisel juhul kurdetakse vestluses mitteosaleva inimese või institutsiooni üle, aga ka olukorra üle, kus vastutajat ei ole, nt kurtmine ilma üle (Pakkanen 2011). Kui probleemi põhjustaja on väljaspool suhtlussituatsiooni, võivad osalejate rollid jaguneda kahel viisil. Mõnikord on tegu kurtja ja reageerijaga, mõnikord kurdavad kõik osalejad ühise probleemi üle.

Näites 1 kurdab lapselaps K vanaemale L, kui raske oli saada tõendit, et talle ei maksta stipendiumi. Probleemi on põhjustanud vestluses mitteosalev ametnik. Vanaema reageerib kurtmisele partiklitega jah ja $m h_{m h}{ }^{3}$

(1) $01 \mathrm{~K}$ : `mina ei `tea. 'tädi on ka nigu mingi `haige kuju, > mis ta arvab 02 et ma akkan nüüd (.) 'jõulu' laupäeval `stippi saama kui ma s- terve 03 se`mestri `saand ei ole [vä.] < $04 \mathrm{~L}$ :

[jah] jah

$05 \quad(0.4)$

$06 \mathrm{~K}$ : 'stippi makstakse ikka st- se'mestri kaupa mitte noh

$07 \mathrm{~L}: \mathrm{mhmh}$

$08 \quad(0.4)$

09 K: mitte selle: (.) 'kuu kaupa.

$10 \mathrm{~L}: \mathrm{jah}$

Siinses artiklis uurime kurtmisjärjendeid, milles on probleemi põhjustanud vestluses mitteosaleja või konkreetset vastutajat ei ole ning vestlusosalised on kurtja ja reageerija. ${ }^{4}$ Sellise kurtmise puhul on oodatud ja eelistatud reaktsioon poolehoiu ja samameelsuse, ühtekuuluvuse väljendamine (ingl sympathy, affiliation), millega vestluskaaslane toetab kurtja hoiakut (nt Drew 1998; Drew, Walker 2009; Selting 2012).

2 Kurtmine põimub suhtluses sageli muude suhtlustegevustega, nt süüdistamisega (Dersley, Wootton 2000; Laforest 2002, 2009) või abipalumisega (Wolfe, Powell 2006).

3 Dialoogid on transkribeeritud vestlusanalüüsi transkriptsioonis, transkriptsioonimärgid on toodud artikli lõpus.

4 Ühiselt arendatud kurtmise kohta vt Rääbis jt 2019. 
Kurtmis- ja reaktsioonivooru on vestlusanalüüsis käsitletud kui naabruspaari (Pomerantz 1984: 63; Schegloff 1988: 122). Naabruspaar on minimaalselt kahest kõnevoorust koosnev dialoogiüksus, mille esiliige nõuab kindlat tüüpi järelliiget, nt palve nõuab täitmist või tagasilükkamist. Järelliikmed võivad jaguneda eelistatud ja mitte-eelistatud variantideks, nt palve täitmine on eelistatud ja tagasilükkamine mitte-eelistatud järelliige.

Kurtmise korral on naabruspaari esiliikmeks kurtmisvoor. Kurtmisvooru ehitamisel kasutatakse mitmesuguseid süntaktilisi, leksikaalseid, prosoodilisi ja retoorilisi vahendeid, mis on eri keeltes suuresti sarnased (vt nt inglise keele kohta Drew, Holt 1988; Drew 1998; poola keele kohta Wyrwas 2002; Kurtyka 2019; saksa keele kohta Selting 2012). Sealjuures ei ole need vahendid kurtmisele ainuomased, kuid esinevad kurtmisjärjendites süstemaatiliselt koos, luues kurtmisvoore, mis väljendavad tugevaid negatiivseid emotsioone ja hoiakuid. Järgnevalt kirjeldame lühidalt eesti keeles kasutatavaid kurtmisvahendeid (vt pikemalt Rääbis jt 2019).

Kurtmine vormistatakse peamiselt negatiivselt markeeritud sõnade ja väljenditega (jama, vastik, raske, paanika, räuskama jm). Kuna kurtja jaoks on oluline näidata, et kurtmine on põhjendatud, kasutatakse lisaks mitmesuguseid tugevdamisvahendeid. Siia kuuluvad intensiivsuspartiklid ja tugevdavad adverbid (nii jube, väga kurb, õudselt vastik jm), samuti viited probleemi pikaajalisusele, kestusele või korduvusele (iga päev, päev otsa, terve aasta jm). Probleemi esitamisel liialdatakse (tuhat asja óppida) kuni äärmusväljendite kasutamiseni (ingl extreme case formulations, Pomerantz 1986) (absoluutselt, üldse, mitte keegi jm). Sageli kasutatakse idioome (karu kõrva peal), hüüatusi (oh sa taevakene) ja vandesõnu (kuradi kurat). Peamine süntaktiline kurtmisvahend on eitus.

Näites 2 kurdab kõneleja V sugulasele telefonis, et pojal läheb muusikaõpetuses halvasti. Voor algab eitavas vormis lausega $(t a=e i=s a a$ abso 'luutselt sellest 'noodiõpetusest 'aru). Kurtja kasutab negatiivse varjundiga sõnu prob leem ja aru `saamatus. Oma väidet tugevdab ta äärmusväljendiga abso 'luutselt, võrdleb edasijõudmist teiste ainetega, kus on $\boldsymbol{k} \tilde{\boldsymbol{o}} \boldsymbol{i} \boldsymbol{k}$ neljad 'viied, ning näitab, et probleem on kestnud pikka aega, terve 'aasta.

(2) $\mathrm{V}$ : .hhhh $\mathrm{ma}=\mathrm{i}=$ 'tea, $\mathrm{ta}=\mathbf{e} \mathbf{i}=\mathbf{s a a}$ abso'luutselt sellest 'noodiõpetusest 'aru või milles prob leem on või on neil 'õpetajaga 'vastastiku aru`saamatus=või. (.) .hhhhh `muidu kõik neljad `viied ja `laulmine e terve `aasta 'kolm. 
Sõnavara ja eituse kõrval on oluline kurtmise väljendamise vahend prosoodia (rõhk, hääletoon, valjus, kõnetempo), samuti naer. Näide 3 pärineb vestlusest, milles isa $\mathrm{M}$ kurdab, et lapsed peavad liiga palju koolitöid arvutis tegema ja arvuti kasutamine kahjustab silmi. ${ }^{5}$ Kurtmisvooru kõige olulisem sõna pime on tugevalt rõhutatud ja valjemalt öeldud. Liialdamist markeerib naerev hääl (naerva hääle kasutamise kohta absurdses olukorras vt Annuka 2020).

(3) M: noo=aga sa- `selleks ajaks kui sa kuskil `tööle lähed oled sa `PIME $\$$ juba peast=ju, sa=i `näe enam $=\mathrm{ju}$ noh? $\$$

Kurtmise keskne retooriline võte on kordused ja parafraasid (näide 3: 'PIME $>s a=i$ 'näe). Kõige sagedasem on varieeritud kordus, milles tihti lisatakse kordamisel tugevdavaid elemente (näide 6: ' $m a=i$ 'maksa $m a=i$ 'akkagi 'maksma üldse), täpne kordus on harvem (näide 14: nad on $n i=$ 'lollid $n i=$ 'lollid).

Tavaline retooriline võte on ka pööratud polaarsusega küsimused, mis ei oota infovastust (vt Koshik 2005; Laanesoo 2012). Näide 4 on pärit samast kurtmisjärjendist kui näide 3. Isa M kurdab, et laps peab koolitööde tegemiseks arvutis istuma, millele külas olev ema sõbranna A reageerib nõustuva partikliga jaa. $\mathrm{M}$ jätkab retoorilise küsimusega no='milleks `seda onju, väljendades seisukohta, et arvutit ei peaks nii palju kasutama.

(4) $01 \mathrm{M}$ : nüüd ta peab `veel arvutis `istuma.

02 A: jaa

$03 \mathrm{M}$ : no=`milleks `seda onju.

Kolmas retooriline võte on võrdlus. Olukorda, mille üle kurdetakse, võidakse võrrelda niihästi kellegi teise parema kui ka sama halva olukorraga (vt ka näide 10). Näites 5 kurdavad vanemad, et lapsel on palju kodutöid. Selles voorus võrdleb ema E lapse edasijõudmist töökaaslase lapse omaga, osutades, et too ei pea tegema nii palju harjutusi.

(5) $\mathrm{E}$ : ja=see: mul `töökaaslase `laps käis eile `siin, ned=pole=vel `uut vihikut `saandki, Joosual juba ` tehtud.

Teiste keelte (nt inglise, prantsuse, poola) kohta on leitud, et kurtja nimetab ka emotsiooni, mille olukord tekitas (nt ingl And I was so angry) (Drew

5 Ainsuse 2. pööre lauses ei viita vestluspartnerile, vaid on potentsiaalsele sündmusele osutav üldisikuline vorm (Erelt 2017: 199). 
1998: 309-311; Traverso 2009; Wyrwas 2002: 36). Meie analüüsitud näidetes nimetati tundeid otsesõnu harva, ainult kolmel korral (vt näide 14: $m=$ täna jälle vihastasin koolis $=j a$ ).

Naabruspaari järelliige annab infot selle kohta, kuidas esiliige on vastu võetud, ning mõjutab ka seda, kuidas see järjend, käsil olev teema või kogu vestlus jätkub. Kurtmises, milles vastutaja on väljaspool suhtlussituatsiooni, on eelistatud reaktsioon poolehoiu väljendamine, millega vestluskaaslane toetab kurtja hoiakut ja emotsiooni. Poolehoiu näitamiseks väljendab vestluspartner oma sarnaseid tundeid (nt annab olukorrale vms samuti negatiivse hinnangu, kasutab markeeritud prosoodiat), arendab kurtmist omalt poolt edasi, räägib enda samalaadsest kogemusest (Drew 1998; Drew, Walker 2009; Traverso 2009; Selting 2012). Mitte-eelistatud reaktsioon on kurtmisega mittenõustumine, mispuhul reageerija vähendab probleemi tõsidust või väljendab kurtjale vastupidist seisukohta (Heinemann, Traverso 2009; Traverso 2009). Poolehoiu väljendamisele või mittenõustumisele lisaks on osutatud, et vestluskaaslane võib küsida lisainfot, anda nõu, pakkuda olukorrale selgitusi (Boxer 1993; Pakkanen 2011). Mitmest naabruspaarist koosneva kurtmise jooksul võib vestluskaaslane reageerida eri viisil: näidata poolehoidu nõrgemalt või tugevamalt, oma hoiakut muuta, mõne seisukoha tagasi lükata, olukorda seletada (Traverso 2009).

Naabruspaari reaktsioonivoor mõjutab ka suhtlejate edasist tegevust. Siin on olulisim see, kas reaktsioonivooru järel naabruspaar, laiem teemajärjend või kogu kurtmine lõpetatakse või seda jätkatakse (Drew, Walker 2009; Traverso 2009). Meie teada ei ole uuritud, kuidas kurtja pärast eri tüüpi reaktsioone jätkab.

Artiklis otsime vastuseid kahele uurimisküsimusele.

1. Kuidas vestluskaaslane kurtmisele verbaalselt reageerib?

2. Kuidas erinevad reaktsioonid mõjutavad seda, kuidas kurtja jätkab?

\section{Materjal ja meetod}

Artiklis analüüsime kooli kohta käivaid kurtmisi. Kool on ühiskonnas väga tavaline kurtmise teema, kuna selle kohta on igaühel oma kogemused, arvamused, hoiakud ja tunded.

Analüüsimaterjal on pärit Tartu Ülikooli suulise eesti keele korpusest. ${ }^{6}$ Korpuse argivestluste hulgas leidus 25 silmast silma ja 32 telefonivestlust,

${ }^{6}$ https://keeleressursid.ee/et/220-suulise-eesti-keele-korpus (22.02.2020). 
milles räägitakse koolist. Neis vestluses oli 40 kurtmisjärjendit. Vestlustes osalevad õpilased, üliõpilased, õpetajad ja nende perekonnaliikmed. Probleemid, mille üle kurdetakse, on raske koolikott, rumalad õpilased, ebaõiglane õpetaja, eesootav eksam, aga ka õppekava sulgemine, korruptsioon ülikoolis jm. Osa muredest puudutab kõnelejat ennast, aga kannataja rollis võib olla ka kurtja laps või sõber. Probleemi põhjustajad on kool ja ülikool kui institutsioonid ning nende esindajad: õpetajad ja ametnikud, aga ka õpilased ja nende vanemad ning kaasüliõpilased.

Uurimismeetod on vestlusanalüüs, mis on empiiriline suhtluse mikroanalüüsi meetod. Iga vooru analüüsitakse eelnevate ja järgnevate voorude ning suhtlustegevuste kaudu, lähtudes suhtlejate endi perspektiivist (Sidnell, Stivers 2013: 77-99).

\section{Reaktsioonivoorud ja kurtmise edasiarendamine}

Järgnevalt uurime kurtmisvoorudele järgnevaid reaktsioonivoore. Analüüsitud voorud jagunevad kuude rühma: poolehoiu väljendamine, seisukoha mittevõtmine, lisainfo küsimine, olukorra seletamine, nõuandmine ja kurtmisega mittenõustumine.

\subsection{Poolehoiu väljendamine}

Eelistatud reaktsioon kurtmisele on eksplitsiitne poolehoiu väljendamine, mida tehakse meie näidetes neljal viisil:

- oma sarnaste emotsioonide ja hoiakute väljendamine,

- samalaadse kogemuse esiletoomine,

- omalt poolt kurtmise edasiarendamine,

- neutraalne nõustumise väljendamine.

Emotsionaalsed ja hoiakulised poolehoiuavaldused toetavad eksplitsiitselt kurtja seisukohta (Drew, Walker 2009; Traverso 2009; Kurtyka 2019). Reageerija väljendab kurtjaga sarnast emotsiooni, kritiseerib kurtmise objekti ( $t a=$ on 'nii 'loll ikka 'minu=meelest=et). Samamoodi nagu kurtmisvoorus kasutatakse ka siin negatiivse konnotatsiooniga sõnu (nõme, loll), tugevdavaid adverbe (jube pikk, nii loll), äärmusväljendeid (sis=tuleb viimnepäev) ja hüüatusi (issand, appikene).

Näide 6 on pärit samast vestlusest kui näited 3-5. Selles katkes räägivad ema $\mathrm{E}$ ja tema sõbranna $\mathrm{A}$. 
(6) 01 E: kui Joosua juba `laulmise eest peab `kakskend=viis krooni käima 02 välja no [sis $\{-\}]$

$03 \mathrm{~A}$ : $\quad$ ['iga 'kuu]=vä.

$04 \quad(0.3)$

$05 \mathrm{E}: \mathrm{ma}=\mathrm{i}={ }^{\prime}$ tea vist jah.

$06 \quad(0.3)$

$07 \mathrm{E}$ : a [`ma=i `maksa ma=i `akkagi `maks]ma üldse.

$08 \mathrm{~A}:<$ [appi kene.] >

$09 \mathrm{E}$ : unusta[gu ‘ära.]

$10 \mathrm{~A}: \quad[\mathrm{se}=\mathbf{o n}=\mathbf{j u}]$ 'nõme ju=et $[\{--\}]$

$11 \mathrm{E}$ :

[\{selge see $\} \mathrm{ma}=\mathrm{i}=$ pand $]$ 'last

12 `selleks sinna `klassi=et=ee `minu käest akatakse `raha pumpam-

Katke alguses alustab ema E vestluses uut teemat, kurtes selle üle, et pojal tuleb kooris käimise eest maksta. Tema voor algab sõnaga kui, mis projitseerib kui-siis-konstruktsiooni. Sõna sis ajal esitab sõbranna A peale rääkides täpsustava küsimuse `iga ` $k u u=v a ̈$ ja saab ebakindla vastuse $m a=i={ }^{\prime}$ tea vist jah (read 01-05). Selle järel jätkab E oma teksti kaudse ähvardusega (read 07, 09). E vooru alguses esitab A taas pealerääkimisega emotsionaalse hinnangu 'appi kene (rida 08), mis on öeldud aeglaselt ja tugevasti rõhutatult. Tema hüüatus on reaktsioon $E$ vastusele real 05 ja laiemalt kurtmisele, et laulmise eest peab maksma. E ei reageeri tema voorule ja A lisab uue, seekord eksplitsiitselt kurtjat toetava hinnangu $s e=o n=j u$ `ñme ju (rida 10). E nõustub selle hinnanguga (rida 11). Tema öeldud selge see näitab ühtlasi, et A öeldu oli endastmõistetav. Pärast seda jätkab E samas voorus sama kurtmisteemaga, tuues esile vastuolu oma esialgse ootuse ja tegelikkuse vahel (read 11-12). Ka teistes meie analüüsitud näidetes arendas kurtja pärast emotsionaalseid toetusavaldusi kurtmist edasi, mitte ei lõpetanud seda (vt ka Traverso 2009: 2393; Rääbis jt 2019: 30). See näitab, et kurtja tõlgendab poolehoiuavaldusi ühtlasi kui toetust kurtmise jätkamisele, mitte kui märguannet kurtmise lõpetamiseks.

Vestluspartner võib oma poolehoidu avaldada ka omalt poolt kurtmist edasi arendades (vt näide 15) või oma samalaadsest kogemusest rääkides ja selle kaudu kurtjaga sarnast hoiakut väljendades (Drew, Walker 2009; Selting 2012). Näites 7 vestlevad kolm tüdrukut. B ja K käivad ühes koolis, $\mathrm{J}$ on $\mathrm{B}$ vanem õde, kes on sama kooli lõpetanud. 
(7) 01 B: mis mis olümpi aadist sa rääkisid, mis `asi see `oli.

02

$03 \mathrm{~K}:$ aa $[\{-\}]$

$04 \mathrm{~B}$ : ['Laudner mää]ris `pähe=sule mida[gi=vä.]

$05 \mathrm{~K}$ : [jah,] (0.4) `eesti keele

06 olümpi aad. jumala värdjas ['mutt. TAHAB]=et ma hakkaks mingit

$07 \mathrm{~B}$ :

[oo.]

$08 \mathrm{~K}$ : `rahva`luulet koguma.

$09 \quad(0.3)$

10 B: aa, ja=tead=mis \$ `mina pean [tegema=vä.] \$

$11 \mathrm{~J}$ :

@ [kroo]oo[oo]@ ((kraaksub, kriiskab))

$12 \mathrm{~B}$ :

['mina pe]an minema

13 'luule 'konkursile järje 'kordselt. (0.5) 'Tartu linna `koolide

14 luule konkursile.

$15 \quad(0.4)$

$16 \mathrm{~J}$ : 'esine[ma=vä.]

17 B: ['meie] (.) tändab=noh (.) jah (.) meie 'koolist võeti sis

18 nagu kaks `tükki onju see kahe ’teistkümnendast see üks `Aivar onju

$19 \mathrm{ja}=$ sis=nagu 'mina onju. (0.5) ma nagu `eelmine aasta võitsin selle

20 'kümnendate klasside `arvestuses võitsin `ära selle (.) kooli selle

21 sisese (0.4) luule 'võistluse $=$ sis (1.2) VÄGA `TORE, .hhhh

$22 @$ noh=et=sis (0.3) ühe $<$ `sügav`mõttelise `luuletuse siis nagu

23 õpime 'pähe $>>$ ja $=$ sis $=$ sellise $<$.hhh humoorika 'jutu et=nagu

$24<$ rahvas `näeks sinu 'tõelist `olemust.> @ (0.4)

25 ma vaatasin siukse `näoga Laudnerile `otsa ni=et (0.6)

$26 \mathrm{no}={ }^{\prime} \mathrm{TORE}=\mathrm{onju}=\mathrm{et}$ sinna ma aint 'igatsekski minna.

Katke algab B küsimusega, millega soovitakse enam infot $\mathrm{K}$ eelnevas jutus mainitud olümpiaadi kohta. $\mathrm{K}$ alustab vastamist, mille katkestab B negatiivset hoiakut sisaldav küsimus selle kohta, kas õpetaja määris talle midagi pähe (rida 04). K kinnitab seda ja alustab kurtmisega õpetaja käsu üle rahvaluulet koguda (rida 06). Selles kasutab ta õpetaja kohta väga teravat hinnangut jumala värdjas ning umbmäärast asesõna mingit, mis kannab sunnitud tegevuse tõttu negatiivset hinnangut. $\mathrm{K}$ vooru järel reageerib B sellele partikliga aa ja alustab seejärel oma kurtmist (read 12-14, 17-26). Ka siin on probleemi tekitaja sama õpetaja ja tema vastumeelsust tekitavad käsud.

Meie näidetes väljendas vestluspartner kurtmisega nõustumist ka neutraalselt. Selleks kasutatakse ennekõike partikleid jaa ja jah, harvemini pikemaid nõustuvaid reaktsioone (nt se=on 'tema moodi; siedasi=on=jah). 
Näites 8 reageerib vestluskaaslane kurtmisele jaa abil. Katke on samast kurtmisjärjendist kui näited 3 ja 4 (samast vestlusest on ka näited 5, 6, 11 ja 13), siin osalevad isa $M$ ja ema sõbranna $A$.

(8) $01 \mathrm{M}:$ aga=no=vaata see=on `kõik siuke `asi=et=no `täna on juba `kõik,

02 .hh täps=samuti `väiksed ’lapsed juba (.) peab 'kõik asjad `arvutis 03 tegema.

$04 \quad$ (.)

05 A: jaa

$06 \mathrm{M}$ : no `kas on seda veel `vaja, tal=on `niigi prillid `ees juba.

Katke alguses alustab M kurtmist selle üle, et lapsed peavad tegema liiga palju koolitöid arvutis. Esimeses voorus kasutab ta kolm korda rõhulisena äärmusväljendit kõik ja tugevdab kurtmist rõhulise omadussõnaga väiksed (read 01-03). Tegelikult on kogu väide liialdatud, kuna probleemi on põhjustanud ainult üks poja töö, mis tuli arvutis teha (see ilmneb varasemast vestlusest). A reageerib kurtmisele nõustuva partikliga jaa (rida 05). Olgu siinkohal siiski öeldud, et üksi vooru moodustav partikkel jah või jaa ei ole alati üheselt tõlgendatav: ta võib märkida seda, et kasutaja aktsepteerib öeldu kui tõe (nt toetudes enda samasugusele teadmisele või kogemusele), aga võib osutada ka tugevamat nõustumist ('ma arvan samamoodi'). M ei lõpeta nõustumise järel lokaalset järjendit, vaid jätkab seda, kasutades pööratud polaarsusega retoorilist küsimust no ’kas on seda veel vaja, mis kordab seisukohta, et nii palju kodutöid ei ole vaja arvutis teha (vt Laanesoo 2012). Samuti ei lõpeta ta kurtmist, vaid toob samas voorus sisse uue aspekti poja prillide kohta, viidates sellele, et arvuti kasutamine on silmadele kahjulik. Ka teistes analüüsitud näidetes jätkus kurtmine peale neutraalset nõustumist. See näitab, et sarnaselt emotsionaalsete toetusavaldustega tõlgendab kurtja ka nõustumist oma hinnangutega ühtlasi kui toetust kurtmise jätkamisele või vähemalt kui jätkamisele vastuseisu puudumist.

\subsection{Seisukoha mittevõtmine}

Järgnevalt vaatleme juhtumeid, kus reageerija kasutab jätkajaid ( $m h m h$, mm, harva ka nii). Jätkajad on partiklid, mis osutavad, et info on vastu võetud ja kasutaja soovib püsida kuulaja rollis. Nad ei võta seisukohta saadud info kohta, ei anna hinnanguid ega osuta ka neutraalset samameelsust kõnelejaga. (Hennoste 2000: 1787-1789) Jätkajaid kasutatakse 
nii kõneleja poolelioleva vooru ajal (näide 9 rida 03) kui ka lõpetatud vooru järel (rida 07). Meid huvitavad siin jätkajad, mis esinevad kõneleja lõpetatud vooru järel.

Näide 9 on samast kurtmisjärjendist kui näide 2. V kurdab telefonis sugulasele $\mathrm{H}$, et pojal on muusikaõpetuses halvad hinded.

(9) $01 \mathrm{~V}$ : sest et noh (0.3) nüüd ta `midagi vastas `järgi, tal oli juba lausa

02 'kahe`seis vahepeal a[ga sis] ta jälle veerandi `lõpp võ='midagi nad $03 \mathrm{H}$ : [mhmh]

$04 \mathrm{~V}$ : säl `tegid, .hhhhh siis ta sai `kolmekese 'kätte aga noh `see on niuke 05 `nõrk `kolm tal sääl.

$06 \quad(0.8)$

$07 \mathrm{H}: \mathbf{m h m h}$

$08 \quad$ (.)

$09 \mathrm{~V}$ : vat `mina olen niukene noh, kah `karu `kõrva=päl ja `maalt `pärit

10 ja `meil nigu suurt ei `õpitud seda `asja ja mina ei `oska seda

11 õpetada kah.

Näitelõigu alguses kurdab V poja hinnete üle (read 01-05), kasutades negatiivsust rõhutavaid fraase ('kolmekese, lausa kahe `seis). V lõpetab oma kurtmise real 05. Järgneb paus, mis näitab soovi voor üle anda, kuid H ei võta vooru, vaid reageerib jätkajaga $m h m h$ (rida 07). Selle järel jätkab V sama kurtmisteemat, tuues esile enda suutmatuse poega õpetada.

Mhmh annab ainult märku sellest, et kasutaja soovib olla edasi kuulaja rollis, väljendamata poolehoidu öeldule. Samas ei anna jätkaja märku selle kohta, kuidas senine kõneleja peaks jätkama. Kõikides analüüsitud näidetes arendas kurtja peale jätkajat kurtmist edasi, mitte ei vahetanud teemat ega saatnud kõnevooru uuesti vestluskaaslasele.

\subsection{Lisainfo küsimine}

Vestluspartner võib kurtmisvoorule reageerida ka küsimusega, et saada lisainfot või täpsustust (Traverso 2009; Pakkanen 2011). Näites 10 vestlevad vanaema $\mathrm{V}$ ja tema lapselapse Peebu elukaaslane $\mathrm{T}$.

(10) $01 \mathrm{~V}$ : kuda=teil läheb kuda=teil=läheb [ $\{$ kodu poole. $\}]$

$02 \mathrm{~T}$ :

$03 \quad(0.3)$

[ooh] ’hästi `töiselt.

$04 \mathrm{~V}$ : hästi='töiselt=läheb jah, 
05 T: hästi töiselt.

$06 \mathrm{~V}$ : `õppimisega ka läheb `ästi võ.=

$07 \mathrm{~T}:=\tilde{o}[\mathrm{o} h \mathrm{~h}]$

$08 \mathrm{~V}:$ [õõ][0̃õhh ]

$09 \mathrm{T:} \quad$ [ei lähe:]

$10 \mathrm{~V}$ : ond $=\tilde{\mathbf{0}} \tilde{\mathbf{o}}$ `raskusi.

$11 \quad(0.5)$

$12 \mathrm{~T}$ : kule=jah (.) `tööl on nii palju vaja käia et,

$13 \mathrm{~V}$ : vot sie `tööl käimine jah ja [sie,]

$14 \mathrm{~T}$ : $\quad$ [e] 'Peebul on täpselt=sama 'moodi

15 ega ma 'üksi ädas ei=ole 'Peep on `ka ju Peep teeb `ka

16 ju aint 'tööd praegu kogu=aeg,

Katke algab V kuidas-läheb-küsimusega, mis ootab eesti keeles üldjuhul pikemat vastust (Rääbis 2009: 113-128; Rumm 2019: 198). Kuna vastaja T piirdub lühivastusega, siis esitab V uue küsimuse õppimise kohta (rida 06), millele saab lühikese negatiivse kurtva vastuse ei lähe: (rida 09). Selle peale jätkab V täpsustava küsimusega ond $=\tilde{o} \tilde{o}$ 'raskusi, millele järgneb T pikem kurtmisvoor, milles ta kurdab nii enda kui ka elukaaslase Peebu raskuste üle (read 12, 14-16). Kuna küsimused ootavad vastust, siis annavad nad kurtjale võimaluse kurtmist jätkata ja arendada.

\subsection{Olukorra seletamine}

Vestluspartner võib kurtmisele reageerida seletusega, milles püüab olukorda või kritiseeritava inimese käitumist põhjendada, tuua esile midagi positiivset ja seada sellega kurtmise vajalikkuse kahtluse alla.

Näites 11 jätkub näites 6 alustatud kurtmisjärjend. Siin osalevad ema E, sõbranna A ja isa M.

(11) $01 \mathrm{E}$ : `õpeta küsib `selle eest `raha kakskend=viis `krooni võ `viiskend 02 krooni=et (.) anda `kooli=polt `lapsele oma `lips ja oma `see (0.4)

03 ü-'ülikonna see::: ['vest]

$04 \mathrm{~A}: \quad$ [jakk] ['vest]

$05 \mathrm{E}:$

[mm] 'vest jah.

06 A: aaa[aa]

$07 \mathrm{E}: \quad[\mathrm{noh}]$

08 M:noo $=[\mathbf{s}=$ oleks kõik ühe`sugused $]$ oleks.

$09 \mathrm{E}$ : [meil on 'kõik `asjad 'olemas noh]

$10 \quad(0.4)$ 
$11 \mathrm{E}$ : mis 'kõik ühesugused

12 A: no mida sa [oskad $\{--\}]$

$13 \mathrm{E}:$

[ja seda lipsu niikuinii ku- kaela pa- panna] ei saada

Näitelõigu alguses sõnastab ema E probleemi: koorivormi eest tuleb maksta. Vooru arendades ta takerdub ja kasutab kaks korda kohatäitjat see, leidmata kohe sõna vest (rida 03). Sõbranna A pakub omalt poolt otsitava kohale sõnu jakk ja vest ning real 05 kinnitab E, et otsitav sõna on vest. Seejärel reageerib A pika emotsionaalse hüüatusega aaaaa (rida 06). E voor on pooleli ning ta proovib seda jätkata hüüatusele peale rääkides (rida 07), kuid nüüd sekkub isa $\mathrm{M}$. Ta toob välja vormi positiivse poole: lapsed oleksid siis ühesugused (rida 08). Sealjuures alustab isa partikliga noo, mis reaktsioonivooru alguses viitab muu hulgas eelnevas voorus esitatud seisukoha tõrjumisele (Keevallik 2016). E hakkab samal ajal põhjendama vormi ebavajalikkust (rida 09). Alles selle järel (rida 11) reageerib ta Mi seletusele ja vaidlustab selle retoorilise küsimusega mis kõik ühesugused. Järgmises voorus jätkab E põhjendamist, miks vorm on tema arvates mõttetu (rida 13).

Ka teistes analüüsitud näidetes lükatakse seletus tagasi või nõustutakse sellega osaliselt ja jätkatakse kurtmist.

\subsection{Nõuandmine}

Kurtmine viitab probleemile ja võib kaasa tuua soovi anda nõu, mida kurtja ise saaks probleemi lahendamiseks teha. Meie materjalis eelneb nõuandele tavaliselt mitu vooru vältav kurtmine. Ühest küljest näitab see, et vestluskaaslane kuulatakse enne lahenduse pakkumist ära. Teisalt on aga oluline, et nõu antakse punktis, kus kurtja on sisse toonud aspekti, mille puhul oleks mingisugune lahendus võimalik. Kuna analüüsitud näidetes kurdetakse probleemide üle, mida kõnelejad ise lahendada ei saa, siis on soovitused pigem naljatavad või kaudset abi pakkuvad.

Näites 12 kurdab õpetajana töötav tütar $\mathrm{H}$ isale $\mathrm{V}$, et lapsevanemad on halbade hinnete pärast vihased. ${ }^{7}$

(12) $01 \mathrm{H}$ : 'vott `seda ma ka ei=tea mis `mulle öeldakse.

02 tõenäoliselt ku 'vanemad näevad=et .hh et on 'üks tunnistusel

03 siis nad järsku `ärkavad=ja .hh \$ 'kõigepealt annavad 'lapsele peksa

\footnotetext{
7 Kurtmisjärjendi algus on näites 14.
} 
04 siis tulevad 'minu kallale. .hh [et=noh] \$

$05 \mathrm{~V}$ :

[noo:] (.) sa pead siss `sõlmima

06 ee=ess=`essiga nigu mingisuguse .hh õmm (2.0) noh, (.)

07 noh nigu nigu 'lepingu=või. .hh

$08 \mathrm{H}$ : mhemhe \$ ei tea jah .hh `koolilt nõudma elu kindlustust. \$

$09 \quad(0.5)$

$10 \mathrm{~V}$ : n:o Eesti Moos näiteks kõik `oma töötajate elud on ‘ära kindlustand

11 ma=i=tea kas `raamatupidajad ka=aga .hh aga need kellel

12 välitöödega pistmist on need on 'kõik kindlustatud.

13 (.)

$14 \mathrm{H}$ : aa.

Katke alguses esitab kurtja H äärmusväite (annab peksa, tulevad kallale), vormistades selle samas naerva häälega, mis viitab öeldu absurdsusele (read 03-04) (vt Annuka 2020). Isa V reageerib tütre vooru katkestades. Tema voor (rida 05) algab partikliga noo, mis viitab järgnevale mitteeelistatud infole (Keevallik 2016), aga siin ka kahtlusele kurtja öeldu tõsikindluses. Sellele järgneb ettepanek sõlmida turvafirmaga leping. Kuna kurtja oli öelnud oma vooru lõpuosa naerva häälega, siis toetab isa absurdne ettepanek teda. Tütar läheb naljaga kaasa ja arendab seda naerva häälega edasi, väljendades sealjuures kahtlust idee mõttekuse üle (rida 08). Peale pausi jätkab isa kindlustuse teemal, viies jutu koolist kõrvale (read 10-12). Tütar reageerib sellele järjendi sulgemisele viitava partikliga $a a$ (rida 14), mis lõpetab ka kurtmise.

Suhtluses võidakse anda ka soovitusi, mis leevendaksid muret kaudselt. Näites 13 kurdavad pereliikmed lapse raske koolikoti üle.

(13) $01 \mathrm{E}$ : tegelt=tal=on `pooled asjad $\{$ veel=sit $\}$ tule`matta.

02 (.)

03 A: 'ei ma `tean=et need on 'rasked, ‘ükskord ta vv-v 'koolist tuli

04 `minu\{ni\}, `ma ütsin `mina seda `seljas küll `kanda ei `jõua.

$05 \mathrm{E}$ : seepärast tal ka seljas `kõverused `sees=ja asjad.

06 A: 'on=vä

$07 \mathrm{E}: * \operatorname{mhm}[\mathrm{h} ?] *$

08 A: [ta] peaks sin 'võimlema ja ve- noh teil on `hea nüd=se 09 'venitus siin.

$10 \quad(0.5)$

$11 \mathrm{~A}$ : et 'rippuda lihtsalt.

$12 \mathrm{M}$ :jah vahest ta 'ripub, ta ütleb küll et=se=on kole 'kõrge.

$13(0.5)$

$14 \mathrm{~J}$ : eih 
$15 \mathrm{~A}: \mathrm{ei}=\mathrm{no}=$

$16 \mathrm{E}$ : =ei `viit[si, noh ta=i 'viitsi.]

$17 \mathrm{M}: \quad \$[\{-\}$ `lõua tõmmab sis $]=$ tab `pinki `jalge alla.

18 [mheh et $\mathrm{se}=$ on parem `tõmmata.] \$

19 A: [\$ aa:::::::: \$ heh]

Ema E on andnud lapse raske koolikoti sõbrannale A tõsta ja täpsustab, et selles pole veel kõiki asju. A nõustub, et asjad on rasked, ja räägib oma kogemusest, kuidas laps raske kotiga tema juurde tuli. Siiani on räägitud ainult kottidest ja asjadest, mida tuleb kaasas kanda. Real 05 toob E sisse uue aspekti, öeldes, et lapsel on raske koti tõttu juba selg kõver. See on A jaoks uus ja üllatav info, millele ta reageerib küsimusega `on=vä. E kinnitab öeldu $m h m h$ abil üle. Kinnituse järel teeb A ettepaneku võimelda (read 08-09). Soovitus on vormistatud kolmandas isikus, mis näitab, et see ei ole suunatud vestluses osalevale lapsele J, vaid vanematele. Tingiv kõneviis osutab kõneleja väikesele õigusele võõra lapse kasvatamise kohta nõu anda (vt Curl, Drew 2008). A ootab vastust (paus real 10), aga keegi ei reageeri. Nüüd lisab A inkremendi (sujuva jätku) et 'rippuda lihtsalt (rida 11). Isa $M$ vastus osutab, et mõte ei ole neile uus, aga samas võtab ta soovituse reservatsiooniga vastu, näidates, et sellega on probleeme. Raske koti üle enam ei kurdeta ja jutt jätkub võimlemise teemal. Selles näites nägime kaudse lahenduse pakkumist: võimlemine oleks küll seljale kasulik, aga ei lahenda põhilist probleemi, et koolikott on raske.

Analüüsitud materjalis lükatakse nõuanded tagasi või nõustutakse reservatsiooniga, kuid kurtmine lõpetatakse. Sellest saab järeldada, et nõuanne ei suuna kurtjat edasi rääkima, vaid on pigem vihje lõpetamisele.

\subsection{Kurtmisega mittenõustumine}

Vestluskaaslane ei pruugi olla kurtja seisukohaga nõus ja võib väljendada teistsugust arvamust. Näites 14 vestlevad isa $H$ ja õpetajana töötav tütar $\mathrm{V}^{8}$

\footnotetext{
${ }^{8}$ Kurtmisjärjendi lõpp on näites 12.
} 
(14) $01 \mathrm{~V}$ : .hhhhh no ja kuis 'teil=läb.

$02 \quad(0.8)$

03 H: noh, mis seal `ikka. m=täna jälle `vihastasin koolis=ja

$04 \quad(0.5)$

$05 \mathrm{~V}$ : miks.

$06 \quad(0.6)$

$07 \mathrm{H}$ : ahh, nad on ni='lollid ni='lollid.

$08 \quad(1.3)$

$09 \mathrm{~V}$ : sellepärast nad `peavadki koolis käima.

$10 \quad(0.5)$

$11 \mathrm{~V}$ : kui nad 'targad oleks kellel neid sinna `tarvis oleks.

$12 \mathrm{H}$ : $\mathrm{mt}=$.hh no: 'oleks=et nad sis 'pingutaks selle nimel et 'targemaks

13 saada aga 'ei. .nhhhhh

$14 \quad(1.2)$

$15 \mathrm{H}: \mathrm{mm} ` \mathrm{~m}: \mathrm{inu}=$ melest neil $=$ on teatavad `puudulikkused.

$16 \quad(0.7)$

$17 \mathrm{~V}$ : kas=see:: tändab terve see `Narva `eesti kogu`kond on üks

18 de'biilikute 'kari. .hhhhhh

$19 \mathrm{H}$ : 'ei, ma=ei=ütle [`seda,]

$20 \mathrm{~V}$ :

$[\{-\}]$ ei $=$ ole

$21 \mathrm{H}: \mathrm{ma}=\mathrm{i}=$ ütle ültse `seda=aga (.) aga seal on teatavad 'tüübid,

22 .hhhhhhhhhh kes nagu (.) ma juba ’lasengi neil täisti .hh tunnis

23 'pleierit kuulata sest=me- 'mina $=\mathrm{ei}=$ taha $\$$ 'nendega tegemist

24 teha `nemad ei=ta `minuga. \$ hh et nad `käivad ja `istuvad

25 seal nimodi 'tundides /---/

Real 01 esitab isa küsimuse no ja kuis 'teil=läb. Tegu on avara neutraalse küsimusega, mis eeldab pikemat vastust ja samas võimaldab tütrel valida teema (vt Thompson jt 2015; Rumm 2018: 304-308). Tütar vastab pärast pausi kinnisfraasiga noh, mis seal `ikka ja hakkab kurtma kooli üle. Ta ei esita fakte, vaid teatab ainult oma emotsiooni (vihastasin), millele eelnev jälle näitab, et probleem on pikaajaline või korduv. Isa küsib vihastamise põhjuse kohta küsisõnaga miks. Miks-küsimused on polüfunktsionaalsed ja nendega saab teha korraga mitut suhtlustegevust. Küsilause vorm võimaldab vastajal tõlgendada seda infoküsimusena ja vastata neutraalselt, kuigi enamasti reageeritakse õigustusega. See osutab, et küsimust tõlgendati negatiivse seisukohavõtuna. (Laanesoo 2017) Selles näites tõlgendab tütar sõna miks kui küsimust põhjuse järele. Selline tõlgendus annab talle võimaluse vastata küsimusele ja sellega kurtmist edasi arendada. Ta annab õpilastele üldistava hinnangu nad on $n i=$ 'ollid $n i=$ 'lollid, 
kasutades halvustavat sõna lollid ja intensiivsuspartiklit nii ning korrates fraasi sama rütmimalliga.

Pärast 1,3-sekundilist pausi (rida 08) vaidlustab isa tütre seisukoha (rida 09). Ta on sellega nõus, et õpilased on lollid, kuid esitab põhjenduse, millega lükkab kurtmise tegelikult tagasi. Tütar ei reageeri ja isa kordab sama mõtet teises sõnastuses (rida 11). Nüüd nõustub tütar reservatsiooniga ja jätkab kurtmist, tuues esile probleemi teise aspekti ja ilmselt ka tuuma - õpilased ei pinguta (read 12-13). Isa ei reageeri sellele ja pärast pikka pausi real 14 tugevdab tütar oma hinnangut, kasutades väljendit neil=on teatavad 'puudulikkused (rida 15) See viitab õpilaste madalale intellektuaalsele tasemele. Nii mõistab seda isa, kes retoorilise küsimuse vormis sõnastab puudulikkused ümber debiilikuteks (read 17-18). Ühtlasi läheb ta teravamaks ja üldistavamaks, omistades tütre hinnangu kogu Narva eesti kogukonnale. Tütar taganeb väljaöeldust ja seletab, mis tunnis toimub. Näeme, et vastuvaidlemine toob kaasa selle, et kurtja aktsepteerib osaliselt vestluskaaslase arvamust, põhjendab ja täpsustab olukorda, aga ei lõpeta kurtmist.

Näites 15 lõpeb vastuvaidlemine sellega, et kurtmine lõpetatakse. Siin räägib ülikoolis õppiv tütar T emale E ja isale I oma koolipäevadest.

(15) $01 \mathrm{E}$ : kas=ee (.) 'keskpäval mingid 'vaheaegasid ka loengute `vahel on. $02(1.0)$

$03 \mathrm{~T}$ : `iga `päev on präegu `nii=et on mingit `augut, aga se=on vä- õudselt 04 vastik.

$05 \quad(0.6)$

06 I: nojah, sa=i=saa kuhugi 'ära ka 'minna, [’oled na]tuke `vahe ja ’jälle $07 \mathrm{~T}$ :

$08 \mathrm{I}$ : uuesti * loeng. *

$09 \quad(0.3)$

$10 \mathrm{E}$ : no siis `saatki natuke `puhatta=ja ['lõogas]ta.

$11 \mathrm{~T}$ :

$12(1.1)$ [mhmh?]

13 I: $\quad$ e=kas seal:=ee `kooli=juures (.) > `süia ka ikka saad, $<$ 14 söökla ` $k a=$ on $=$ teil $=$ võ.

Näitelõik algab sellega, et ema esitab neutraalse küsimuse loengute vaheaegade kohta (rida 01). Tütre voor koosneb kahest osast. Esimene osa on vastus küsimusele. Samas lisab tütar sellesse negatiivsele suhtumisele viitavat ainest, kasutades fraase iga päev ja mingid augud (vrd ema öeldud 
positiivse konnotatsiooniga sõna vaheajad). Sõnastus toob esile, et tema jaoks on tegu probleemiga. Vastuse teine pool $s e=$ on $v \ddot{a}-\tilde{\text { oudselt }}$ vastik toob sisse eksplitsiitse negatiivse hinnangu (read 03-04). Poolelijäänud sõna $v \ddot{a}$ - on tõenäoliselt sõna $v \ddot{a} g a$ algus, mis asendatakse tugevama sõnaga oudselt. Kurtmine aukude üle osutab, et probleemi põhjustaja ei ole tütar ise, vaid tunniplaani koostajad.

Isa I väljendab poolehoidu, arendades tütre kurtmist edasi ja põhjendades, miks selline olukord on ebameeldiv (read 06, 08). Edasiarendamine on üks tavalisi poolehoiu väljendamise viise (vt samalaadse kogemuse kasutuse kohta näide 7). Sealjuures formuleerib ta põhjenduse tütre seisukohalt. Tütar reageerib sellele kinnitava partikliga $\mathrm{mhmh}$.

Real 10 esitab ema E teistsuguse seisukoha, mis eitab probleemi või vähemalt vähendab selle tõsidust: vaheaegade ajal saab puhata, järelikult on need head. Tütar reageerib ka sellele $m h m h$ abil (rida 11). Vestluses tekib pikk paus, mille järel tütar kurtmist edasi ei arenda. Ka tütre kurtmist edasi viinud isa ei jätka kurtmisega, vaid alustab uut teemat (read 13-14). Selle näite puhul võib öelda, et isa ja ema seisukohad on erinevad, kuid kumbagi ei saa tõlgendada väärana. Oluline on siin asjaolu, et kurtja seisukohta vaidlustava arusaama järel kurtmine lõpetatakse. Sealjuures tõlgendavad nii kurtja kui ka kurtmise edasiarendaja vaidlustust lõpetamise märguandena.

Näited tõid esile, et kurtmise vaidlustamise järel minnakse edasi kahel viisil. Näites 14 aktsepteerib kurtja osaliselt vestluskaaslase arvamust, kuid jätkab kurtmist. Näites 15 reageerib kurtja vastukäivale seisukohale nõrga nõustumisega ja lõpetab kurtmise. Analüüsitavas materjalis ei ole näiteid, kus kurtja otseselt nõustuks vestluskaaslase vastupidise seisukohaga.

\section{Kokkuvõte}

Artiklis käsitlesime kurtmisjärjendeid argivestlustes, mille teema on kool ja probleemi allikas on väljaspool suhtlussituatsiooni: kool kui institutsioon, õpetajad, ametnikud, õpilased ja nende vanemad, kaasüliõpilased. Kõik analüüsitud kurtmisjärjendid koosnesid mitmest naabruspaarist, mille esiliige sisaldas kurtmist ja järelliige sellele reageerimist. Otsisime vastuseid kahele küsimusele: kuidas vestluskaaslane kurtmisele verbaalselt reageerib ja kuidas erinevad reaktsioonid mõjutavad seda, kuidas kurtja jätkab. 
Esiteks esitasime erinevad viisid, kuidas kurtmisele reageeritakse. Keskne ja eelistatud reaktsioon kurtmisele on poolehoiu väljendamine. Vestluskaaslane väljendab kurtjaga sarnast emotsiooni ja kritiseerib kurtmise objekti (näide 6), räägib enda samalaadsest kogemusest (näide 7), arendab kurtmist edasi (näide 15) või väljendab poolehoidu neutraalsete nõustuvate dialoogipartiklitega (näide 8). Mitte-eelistatud reaktsioon on kurtmisega mittenõustumine, mille korral vestluskaaslane vaidlustab kurtja seisukoha (näited 14 ja 15). Poolehoiu väljendamise ja mittenõustumise vahele jäävad näited, milles kaaslane ei võta seisukohta, vaid kasutab neutraalset jätkajat (näide 9). Kokku moodustavad need reaktsioonid skaala poolehoiu väljendamine - seisukoha mittevõtmine - vaidlustamine. Lisaks küsisid vestluspartnerid kurtjalt lisainfot (näide 10), pakkusid talle seletusi ja põhjendusi (näide 11) või nõuandeid probleemi lahendamiseks (näited 12 ja 13).

Varasemates uurimustes ei ole meie teada neutraalse jätkaja kasutamist täheldatud. Muud eesti materjalis leidunud reageerimisviisid on samasugused, nagu on leitud teistes uuritud keeltes ja kultuurides. Seega võib järeldada, et nii nagu kurtmisvooru vormistamise keelelised vahendid, on ka reageerimisel kasutatavad suhtlustegevused ja keelelised vahendid küllalt universaalsed.

Teiseks tõime välja, kuidas erinevad reaktsioonid mõjutavad kurtja jätkamist. Analüüs kinnitas teistes keeltes saadud tulemusi, et kurtmine jätkub peale vestluskaaslase poolehoiuväljendusi (näited 6-8) ja peale lisainfot soovivaid küsimusi (näide 10). Selle kõrval esitasime ka variandid, mida varem meie teada ei ole uuritud. Kurtmine jätkus ka neutraalse jätkaja järel (näide 9) ja peale vestluspartneri pakutud seletusi (näide 11). Kurtmisega mittenõustumine tõi kaasa erinevaid jätkamisvariante: kurtmine kas lõpetati (näide 15) või seda jätkati (näide 14). Kurtmine lõpetati alati nõuannete järel (näited 12 ja 13).

Tulemustest ilmneb, et reageerimisviisid ei ole võrdsed. Küsimused ja poolehoiuavaldused suunavad kurtjat jätkama. Küsimused ootavad suhtlusnormi järgi vastust ning annavad sellega võimaluse kurtmist jätkata ja arendada. Vestluskaaslase poolehoiuavaldusi võib ühtlasi tõlgendada toetusena kurtmise kui suhtlustegevuse jätkamisele. Neutraalse jätkaja järel on kõnelejal võimalus valida, kas jätkata kurtmist, valida uus teema või saata kõnevoor uuesti vestluskaaslasele tagasi. Kurtja valib ka sel juhul jätkamise. 
Seletused, põhjendused ja mittenõustumine tõstavad esile, et kurtmine on vestluskaaslase arvates alusetu, ja suunavad teda kurtmise lõpetamise poole. Siinsetes näidetes lükkab kurtja seletused tagasi või nõustub nendega osaliselt. Samuti aktsepteerib ta osaliselt vestluskaaslase erinevat arusaama. See võimaldab kurtjal jätkata, kuna tema seisukohast on kurtmine vähemalt osaliselt õigustatud ja põhjendatud. Samas võib kurtja ka lõpetada.

Muudest reageerimisviisidest erineb kurtja käitumine nõuannete korral. Ka need lükatakse tagasi või nendega nõustutakse reservatsiooniga, kuid kurtmine lõpetatakse. Seega võib järeldada, et kurtja tõlgendab neid kui tugevaid kurtmise lõpetamise signaale. Nõuandmine on argivestluses problemaatiline suhtlustegevus, kuna toob esile osalejate asümmeetria. Nõuandja näitab, et tal on teadmised, mis teisel inimesel puuduvad, ja pakub välja tegevussuuna, mida ta ise sobivaks peab. Nõu antakse ootusega, et saaja arvates on see asjakohane, abistav ja aktsepteeritav. (Jefferson, Lee 1981; Vehviläinen 2001:373) Samas kurdetakse meie analüüsitud näidetes probleemide üle, mida kõnelejad tegelikult lahendada ei saa, ja sellisena on nõuanded praktiliselt kasutud.

Praegusi tulemusi üldistades saame väita, et mitme võimaluse korral kaldub kurtja valima jätkamist. Samas viivad reageerimisviisid, mis suunavad kurtjat lõpetama, erinevatele tulemustele. See teema vajab aga suurema materjali detailsemat analüüsi.

\section{Transkriptsioonimärgid}

$\begin{array}{ll}. & \text { langev intonatsioon } \\ , & \text { poollangev intonatsioon } \\ ? & \text { tõusev intonatsioon } \\ (.) & \text { mikropaus }(0,2 \text { sek või lühem }) \\ (0.5) & \text { pausi pikkus sekundites } \\ \text { sõna } & \text { rõhutamine } \\ {[]} & \text { pealerääkimine } \\ = & \text { kahe iseseisva üksuse kokkuhääldamine } \\ >< & \text { kiirendatud lõik } \\ <> & \text { aeglustatud lõik } \\ * * & \text { vaiksem lõik } \\ \text { SÕNA } & \text { valjem lõik } \\ \text { e::i } & \text { hääliku venitus }\end{array}$


sipoolelijäänud sõna

mhemhe naer

$\mathrm{s}(\mathrm{h})$ õna naerdes lausutud sõna

@ @ hääletooni muutumine

\$ \$ naerev hääl

.hh sissehingamine

.nhh ninaga tõmbamine sissepoole

mt matsutamine

\{sõna\} ebaselgelt kuuldud sõna või lõik

$\{-\} \quad$ ebaselgeks jäänud sõna

$\{--\} \quad$ pikem ebaselgeks jäänud lõik

(( )) transkribeerija kommentaar

/---/ näitest välja jäetud read

\section{Kirjandus}

Annuka, Andra 2020. Naerev hääl ametlikus ja argivestluses. - Eesti Rakenduslingvistika Ühingu aastaraamat 16.

Boxer, Diana 1993. Social distance and speech behavior: The case of indirect complaints. - Journal of Pragmatics 19 (2), 103-125. https://doi. org/10.1016/0378-2166(93)90084-3

Curl, Traci, Paul Drew 2008. Contingency and action: A comparison of two forms of requesting. - Research on Language and Social Interaction 41 (2), 129-153. https://doi.org/10.1080/08351810802028613

Dersley, Ian, Anthony J. Wootton 2000. Complaint sequences within antagonistic argument. - Research on Language and Social Interaction 33 (4), 375-406. http://dx.doi.org/10.1207/S15327973RLSI3304_02

Drew, Paul 1998. Complaints about transgressions and misconduct. - Research on Language and Social Interaction 31 (3-4), 295-325. https://doi.org/10. 1080/08351813.1998.9683595

Drew, Paul, Elisabeth Holt 1988. Complainable matters: The use of idiomatic expressions in making complaints. - Social Problems 35 (4), 398-417. https://doi.org/10.2307/800594

Drew, Paul, Traci Walker 2009. Going too far: Complaining, escalating and disaffiliation. - Journal of Pragmatics 41 (12), 2400-2414. https://doi. org/10.1016/j.pragma.2008.09.046

Erelt, Mati 2017. Öeldis. - Eesti keele süntaks. Toim. M. Erelt, H. Metslang. (=Eesti keele varamu III.) Tartu: Tartu Ülikooli Kirjastus, 93-239.

Heinemann, Trine, Véronique Traverso 2009. Complaining in interaction: Introduction. - Journal of Pragmatics 41 (12), 2381-2384. https://doi. org/10.1016/j.pragma.2008.10.006 
Hennoste, Tiit 2000. Sissejuhatus suulisesse eesti keelde IV. Suulise kõne erisõnavara 3. Partiklid. - Akadeemia 8, 1773-1806.

Jefferson, Gail, John R. E. Lee 1981. The rejection of advice: Managing the problematic convergence of a 'troubles-telling' and a 'service encounter'. Journal of Pragmatics, 5 (5), 399-422. https://doi.org/10.1016/03782166(81)90026-6

Keevallik, Leelo 2016. Estonian $n o(o)(h)$ in turns and sequences: Families of function. - NU / NÅ. A Family of Discourse Markers Across the Languages of Europe and Beyond. Ed. by P. Auer, Y. Maschler. Berlin, Boston: de Gruyter, 213-242.

Koshik, Irene 2005. Beyond Rhetorical Questions: Assertive Questions in Everyday Interaction. Amsterdam: John Benjamins. http://dx.doi.org/10.1075/ sidag. 16

Kurtyka, Andrzej 2019. I complain, therefore I am: On indirect complaints in Polish. - Journal of Pragmatics 153, 34-45. https://doi.org/10.1016/j. pragma.2019.04.009

Laanesoo, Kirsi 2012. Pööratud polaarsusega retoorilised küsimused argivestluses. - Keel ja Kirjandus 7, 499-517.

Laanesoo, Kirsi 2017. A miks sa torusse ei räägi? Miks-küsilausetega tehtavad suhtlustegevused argitelefonivestlustes. - Eesti Rakenduslingvistika Ühingu aastaraamat 13. Toim. Margit Langemets, Maria-Maren Linkgreim, Helle Metslang. Tallinn: Eesti Rakenduslingvistika Ühing, 89-105. doi:10.5128/ERYa13.06

Laforest, Marty 2002. Scenes of family life: Complaining in everyday conversation. - Journal of Pragmatics 34 (10-11), 1595-1620. https://doi. org/10.1016/S0378-2166(02)00077-2

Laforest, Marty 2009. Complaining in front of a witness: Aspects of blaming others for their behaviour in multi-party family interactions. Journal of Pragmatics 41 (12), 2452-2464. https://doi.org/10.1016/j. pragma.2008.09.043

Pakkanen, Marjatta 2011. Student teachers' indirect complaining in learning groups. - Teachers and Teaching: Theory and Practice 17 (3), 383-394. https://doi.org/10.1080/13540602.2011.554715

Pomerantz, Anita 1984. Agreeing and disagreeing with assessments: Some features of preferred/dispreferred turn shapes. - Structures of Social Action: Studies in Conversation Analysis. Ed. by J. Maxwell Atkinson, John Heritage. Cambridge: Cambridge University Press, 57-101.

Pomerantz, Anita 1986. Extreme case formulations: A way of legitimizing claims. - Human Studies 9 (2-3), 219-230.

Rumm, Andra 2018. Kas vastata lühidalt või pikalt? Avatud küsimuste vastused eesti suulises suhtluses. - Keel ja Kirjandus 4, 297-313. 
Rumm, Andra 2019. Avatud küsimused ja nende vastused eesti suulises argivestluses. (= Dissertationes Linguisticae Universitatis Tartuensis 36.) Tartu: Tartu Ülikooli Kirjastus.

Rääbis, Andriela 2009. Eesti telefonivestluste sissejuhatus: struktuur ja suhtlusfunktsioonid. (= Dissertationes Linguisticae Universitatis Tartuensis 13.) Tartu: Tartu Ülikooli Kirjastus.

Rääbis, Andriela, Tiit Hennoste, Andra Rumm 2018. Co-constructing complaints about school in Estonian everyday conversations. -5 th International Conference on Conversation Analysis, 11.-15.07.2018, Loughborough. Loughborough University, 279-280.

Rääbis, Andriela, Tiit Hennoste, Andra Rumm, Kirsi Laanesoo 2019. They are so stupid, so stupid. Emotional affect in Estonian school-related complaints. - Journal of Pragmatics 153, 20-33. https://doi.org/10.1016/j. pragma.2019.02.016

Schegloff, Emanuel A. 1988. Goffman and the analysis of conversation. - Erving Goffman. Exploring the Interaction Order. Ed. by Paul Drew, Anthony J. Wootton. Cambridge: Polity Press, 89-135.

Selting, Margret 2012. Complaint stories and subsequent complaint stories with affect displays. - Journal of Pragmatics 44 (4), 387-415. https://doi. org/10.1016/j.pragma.2012.01.005

Sidnell, Jack, Tanya Stivers (eds.) 2013. The Handbook of Conversation Analysis. Chichester: Wiley-Blackwell. http://dx.doi.org/10.1002/ 9781118325001

Thompson, Sandra A., Barbara A. Fox, Elizabeth Couper-Kuhlen 2015. Grammar in Everyday Talk: Building Responsive Actions. (= Studies in Interactional Sociolinguistics 31.) Cambridge: Cambridge University Press. http://dx.doi.org/10.1017/CBO9781139381154

Traverso, Véronique 2009. The dilemmas of third-party complaints in conversation between friends. - Journal of Pragmatics 41 (12), 2385-2399. https:// doi.org/10.1016/j.pragma.2008.09.047

Vehviläinen, Sanna 2001. Evaluative advice in educational counseling: The use of disagreement in the "stepwise entry" to advice. - Research on Language and Social Interaction 34 (3), 371-398. https://doi.org/10.1207/ S15327973RLSI34-3_4

Wolfe, Joanna, Elizabeth Powell 2006. Gender and expressions of dissatisfaction: A study of complaining in mixed-gendered student work groups. Women and Language 29, 13-20.

Wyrwas, Katarzyna 2002. Skarga jako gatunek mowy [Complaint as a Genre of Speech]. Katowice: Wydawnictwo Uniwersytetu Śląskiego. 


\title{
Responses to school-related complaints in Estonian everyday conversations
}

\author{
ANDRIELA RÄÄBIS, TIIT HENNOSTE, \\ KIRSI LAANESOO, ANDRA RUMM
}

The article targets complaint sequences in Estonian everyday conversations with a focus on responses to complaints. A complaint is a social action by which speakers express dissatisfaction with a certain state of affairs. The aim of complaining is to show that the matter is worth complaining about and to get affiliation from the recipient. For this research 40 school-related complaint sequences were studied. The purpose of this research was to find out how recipients respond to complaints and how different responses affect the course of the complaining.

The preferred response to complaining is displaying affiliation with the complainant. This is accomplished either by recipients displaying the same emotion towards the complainable matter, talking about a similar experience, developing the complaint further or agreeing neutrally. This kind of responses are followed by continuation of complaining. Responses that do not convey any stance towards the complaint, such as the continuer $m h m h$, show that the recipient is listening and are also followed by continuation of complaining. Another type of response that gives the complainant an opportunity to continue the complaint is recipients asking follow-up questions. Additionally, there occurred three types of non-preferred responses in our data: accounting for the complainable matter, giving advice to complainants and dismissing the complaint. In the case of non-preferred responses, complainants reject the advice, do not accept the account for the complainable matter nor the dismissal of the complaint. Our analysis shows that complaining is continued after accounts and often after dismissals of the complaint. In our data, the complaint sequence gets closed after the recipient's advice-giving and sometimes after dismissals of the complaint.

Keywords: conversation analysis, complaint, sequence, Estonian 
Andriela Rääbis

Eesti ja üldkeeleteaduse instituut

Tartu Ülikool

Jakobi 2

51014 Tartu

andriela.raabis@ut.ee

Tiit Hennoste

Eesti ja üldkeeleteaduse instituut Tartu Ülikool

Jakobi 2

51014 Tartu

tiit.hennoste@ut.ee

Kirsi Laanesoo

Eesti ja üldkeeleteaduse instituut Tartu Ülikool

Jakobi 2

51014 Tartu

kirsi.laaanesoo@ut.ee

Andra Rumm

Eesti ja üldkeeleteaduse instituut

Tartu Ülikool

Jakobi 2

51014 Tartu

andra.rumm@ut.ee 